\title{
Cultura Digital: Transformação bancária sob a perspectiva do Design de Serviços
}

\author{
Digital Culture: Banking Transformation from the Service Design Perspective
}

OLIVEIRA, José Nilson Batista de; Mestrando em Design; Universidade de Brasília

nilsonjboliveira@gmail.com

MAYNARDES, Ana Cláudia; Doutora em Artes; Universidade de Brasília

anacmay@gmail.com

\section{Resumo}

A conectividade por meio da internet trouxe às diferentes culturas a oportunidade de conhecer diversos serviços disponíveis no mercado. No processo de transculturação, têm ocorrido mudanças nos comportamentos sociais das gerações. Este artigo trata de um estudo para entender como os usuários, da geração digital, se relacionam com as tecnologias digitais, em especial as bancárias. Por meio de levantamento teórico tendo como base HALL (2006) e PRENSKY (2001) será realizada uma revisão dos conceitos de Cultura Digital e dos estudos que analisam os comportamentos das pessoas conectadas na internet. Entender, por meio do Design de Serviços, os desejos e usos da geração digital e como o setor financeiro tem evoluído, contribuem para a compreensão de um dos principais artefatos ofertados à sociedade: o aplicativo para smartphones que possibilita consultas, transações e aquisições de produtos e serviços bancários.

Palavras Chave: Cultura Digital; Comportamento; Banco digital.

\begin{abstract}
Connectivity through the internet has brought different cultures the opportunity to learn about the many services available in the market. In the process of transculturation, there have been changes in the social behaviors of the generations. This article is about a study to understand how digital generation users relate to digital technologies, especially banking. A theoretical review based on HALL (2006) and PRENSKY (2001) will review the concepts of Digital Culture and the studies that analyze the behaviors of people connected to the Internet. Understanding, through Service Design, the desires and uses of digital generation and how the financial sector has evolved, contribute to the understanding of one of the main artifacts offered to society: the application for smartphones that enables consultations, transactions and acquisitions of products and banking services.
\end{abstract}

Keywords: Digital Culture; Behavior; Digital banking. 


\section{Introdução}

Quando estamos presencialmente com outra pessoa, seja em uma reunião de trabalho, lazer ou até mesmo em uma negociação comercial, é natural, tanto para nós quanto para o interlocutor acessarmos mais de uma vez o smartphone ${ }^{1}$, por exemplo, para responder alguma mensagem ou ler algum e-mail importante. Essa atitude, considerada por alguns como ato de uma pessoa mal-educada ou de que não se faz presente no momento em que se está, para usuários (as) deste tipo de tecnologia, passa despercebida a quantidade de vezes que eles (as) interagem com seus aplicativos, pois estão acostumados (as) a realizarem múltiplas tarefas simultaneamente (Prensky 2001). Se observarmos o que acontece nessas interações, veremos que foram solucionados problemas, vendas foram concluídas, informação importante foi transmitida, um resultado ou um relatório foi checado. Essa é uma característica da mobilidade, não apenas da tecnologia smartphone, mas também do usuário, que tem a possiblidade de interagir com outras pessoas em diversos lugares. O que demonstra a versatilidade e velocidade com que as pessoas pertencentes à Geração Digital se relacionam com os artefatos digitais. Há, no entanto, que se registrar que não se generaliza o cenário descrito; há também situações em que o uso de tecnologias digitais ${ }^{2}$, traz comportamentos considerados inadequados para a sociedade (Palfrey e Gasser 2017), e isso, lógico, no uso de qualquer artefato em que não se estabelece os critérios convencionais de uma cultura.

De acordo com a pesquisa do Cetic.br (2016), moradores que acessam a internet pelo smartphone todos os dias ou quase todos os dias, da zona urbana e rural, são de $83 \%$ e $65 \%$ respectivamente. Esses dados demonstram a representatividade que os smartphones ocupam na vida das pessoas. A conectividade por meio dos aplicativos para smartphones proporciona aos seus usuários acessos contínuos e em diversos lugares, diferentemente dos computadores em que o uso é restrito ao local de trabalho ou às residências. $O$ advento da mobilidade do acesso à internet e, consequentemente, às informações, vídeos, mensagens instantâneas, artes, cultura e tantas outras funcionalidades disponíveis na palma da mão, mudou os modelos de pensamentos dos indivíduos que nasceram com acessos às tecnologias digitais, afirma Prensky (2001).

É possível propor a existência da terminologia Cultura Digital (GERE, 2011), na medida em que o termo "digital" pode representar a maneira que vivemos hoje como um marco histórico, pois engloba os artefatos e sistemas de significação e comunicação que demarcam mais claramente nosso estilo de vida contemporâneo. A existência de tecnologias digitais, a exemplo de aplicativos para smartphones, a maneira como as pessoas acessam informações ou as produzem diferenciam de períodos anteriores, como no alcance e na aceitação. A funcionalidade push, por exemplo, é uma maneira de interação com os usuários, na qual eles acessam as informações por meio de uma notificação e são chamados a interatuar.

A Geração Digital é aqui definida como pessoas que têm acesso e usam de maneira sistemática as tecnologias digitais para smartphones. Prensky (2001) cita dois tipos de geração: Nativos e Imigrantes Digitais. Os Nativos Digitais são aqueles que nasceram e tiveram acessos às tecnologias digitais desde crianças, já os imigrantes digitais passaram a ter acesso depois da fase

\footnotetext{
${ }^{1}$ Neste artigo adotamos a terminologia smartphone (telefone inteligente) por abranger funcionalidades de aplicativos, conexão de internet sem fio e de maior amplitude que o convencional celular (apenas ligações e mensagens).

${ }^{2}$ Usaremos a terminologia, tecnologias digitais, para referirmos aos aplicativos disponíveis em smartphones.
} 
adulta. É importante ressaltar que, tais terminologias, unicamente, não visam decodificar os comportamentos dos usuários digitais, uma vez que são apenas uma das variáveis a serem analisadas no comportamento humano, conforme apontam Simões e Gouveia (2008):

\section{É importante salientar que da tentativa de caracterização de uma geração, como um todo, não é legitimo extraírem-se ilações sobre as características de uma pessoa, apenas com base na sua pertença a essa geração. $O$ grupo geracional a que um indivíduo pertence é apenas mais uma das muitas variáveis que é preciso ter-se em conta na sua caracterização, ao lado do gênero, da idade, do nível de escolaridade ou da classe social. (SIMÕES, L. e GOUVEIA, L., 2008, p. 01).}

As redes sociais, como Facebook e Instagram; as plataformas de vídeos, como Youtube e Vimeo; e os aplicativos de mensagens instantâneas, como WhatsApp e Telegram são algumas das tecnologias digitais que os usuários da Geração Digital têm acesso para emitir e receber informação, construir conteúdos e comunicar. Segundo o IBGE (2016) o percentual de acesso à internet, nos domićlios, por meio de smartphones é de $80,4 \%$ ante $76,6 \%$ por meio do computador (AGÊNCIA BRASIL, 2016). Esse percentual de acessos por meio de smartphones demonstra a tendência do brasileiro em acessar os serviços digitais, na sua maioria, por esse meio (Figura 1). O uso de smartphones, além de facilitar o acesso imediato e em diferentes localizações, possibilitou a criação de diversos tipos de aplicativos, que auxiliam as pessoas em diversos aspectos da vida, como por exemplo: aplicativos de informações sobre estado de saúde, trânsito, tempo, aplicativos de música, redes sociais, despertador, agenda sincronizada online com outros usuários, aplicativos de compras coletivas, aplicativos bancários, dentre outros.

Figura 1: O celular para navegar na rede era usado em $80,4 \%$ das casas com acesso à internet, já o computador para esse fim estava em 76,6\% desses domicílios e teve queda em comparação com 2013 (88,4\%).

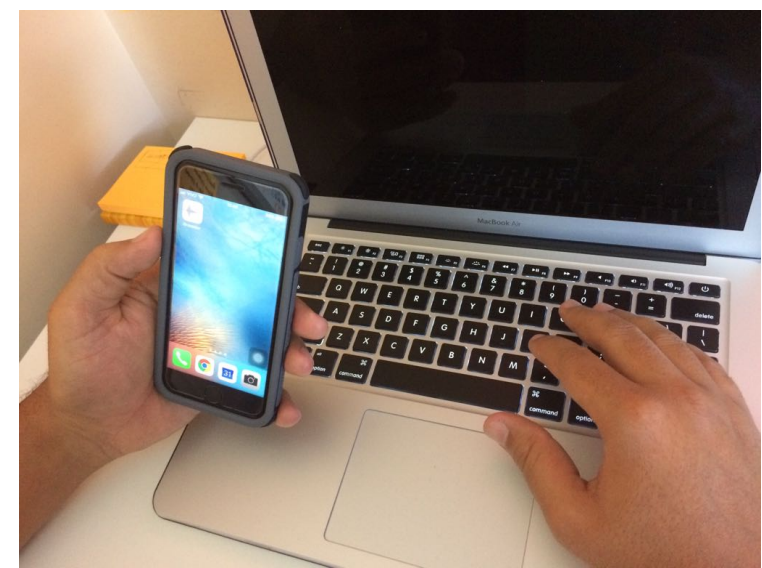

Fonte: Agência Brasil. Foto: Arquivo próprio dos autores.

Com a possibilidade de desenvolvimento de diversos aplicativos, a indústria financeira se apropriou das funcionalidades disponíveis em smartphones para seus clientes. Todavia, o relacionamento das pessoas com bancos é comumente traduzido pela insatisfação, juros altos, tarifas elevadas e atendimento precário. Esse cenário demonstra um pouco do que as pessoas lembram e pensam de uma instituição que faz a intermediação financeira e comercialização de produtos e serviços. Os bancos, por sua vez, buscam fortemente no mercado a rentabilidade, a eficiência operacional e os resultados para seus acionistas. Essa situação tem mudado nos últimos anos nesta indústria, na qual o consumidor, exposto a serviços que têm oferecido experiência de 
uso constantemente, consideradas de excelência (ex. Google, Amazon, Apple, Samsung e etc.), está ávido por serviços que sejam iguais ou melhores do que as que usam, possam pagar apenas por aquilo que realmente usufruem e possam ser atendidos em horários diferentes daqueles convencionalmente estabelecidos para o setor.

Essa exigência causou no setor a necessidade de se transformar, buscar melhorar a experiência do usuário e satisfazer necessidades, antes não consideradas, o core business do sistema. Nesta corrida pela transformação ficou evidente a necessidade da utilização de tecnologias digitais, da entrega de serviços ao cliente por meio de aplicativos para smartphones. Desta vez, não mais para tirá-lo da agência, para fazer apenas transações, como transferências e consultas, mas também para fomentar negócios como empréstimos, vendas de produtos de seguridade, capitalização e outros, inclusive, com assessoramento humano por meio de chat, vídeo conferência e escritório digital, na tentativa de eliminar as barreiras antes existentes no relacionamento cliente e banco.

Para tanto, o presente artigo apresenta um estudo acerca do uso de tecnologias digitais e a relação das pessoas com elas. Apresentaremos também conceitos teóricos sobre identidade nacional e cultura, e em que contexto o setor financeiro está, no que diz respeito à transformação digital e ao atendimento às expectativas de seus usuários.

\title{
2 Relação entre cultura, identidade nacional e tecnologias digitais
}

O indivíduo vive em sociedade; é parte de um todo e tem sua singularidade neste todo. Uma cultura é formada por diversos fatores compreendidos em uma sociedade, independentemente de como ela possa ser classificada. Para Bauman (2012), o que existe é uma variedade cultural das sociedades e não a variedade de culturas; o autor descreve essa variedade cultural como uma condição existente, independente de aceitação ou rejeição de uma forma cultural. Com a globalização, a sociedade atual vive em contato constante com diferentes culturas, com mais predominância, os países da Periferia vivem maior o processo de transculturação advindo dos países do Centro ${ }^{3}$.

lanni (1996) cita sobre o processo de transculturação e apresenta de maneira clara como acontece, por meio de aspectos sociais, em nossa sociedade, as relações interculturais entre pessoas de diferentes países:

\begin{abstract}
A transculturação pode ser o resultado da conquista e dominação, mas também da interdependência e acomodação, sempre compreendendo tensões, mutilações e transfigurações. Tantas são as formas e possibilidades de intercâmbio sociocultural, que são muitas as suas denominações: difusão, assimilação, aculturação, hibridação, sincretismo, mestiçagem e outras, nas quais se buscam peculiaridades e mediações relativas ao que domina e subordina, impõe e submete, mutila e protesta, recria e transforma. (IANNI, 1996, p. 154 grifo nosso).
\end{abstract}

Esse processo de transculturação, embora, não à maneira opressora, ao menos, visível e não a que queremos explorar neste artigo, pois focamos no que diz respeito às tecnologias digitais, é aquela que acontece por meio da globalização, em que as pessoas estão em contato constante com uma variedade cultural de diferentes países e recebem ou são influenciadas por

\footnotetext{
${ }^{3}$ As terminologias países do Centro e da Periferia, adotadas neste artigo, foram conceituadas por Bonsiepe (2011) no sentido político e não geográfico, sendo, os países da Periferia aqueles já foram denominados países em desenvolvimento, subdesenvolvidos ou ainda de Terceiro Mundo.
} 
elementos diferentes das de seu país de origem. Para a realidade atual, vemos o processo de transculturação fazer sentido, no que tange ao que Bonsiepe (2011) expõe: os países do Centro continuam a dominar os países da Periferia. Para o que trazemos em questão, é o que lanni (1996) cita como "recria e transforma"; as tecnologias advindas dos países do Centro contribuíram para transformação digital da Periferia. Isso porque os países do Centro detêm e estão na vanguarda das tecnologias digitais mais avançadas do mundo. Por exemplo, empresas como Facebook, Apple e Google instalaram suas sedes, diversas startups ${ }^{4}$ de diferentes países do mundo nascem e até mesmo empresas do setor financeiro como Banco do Brasil S.A tem um laboratório (LABB) para "disseminar a cultura digital" (Banco do Brasil, 2016) no Vale do Silício (Califórnia-Estados Unidos). A Universidade Cornell apresenta um relatório que aponta os países do Centro, como por exemplo, Suíça, Suécia, Países Baixos, Estados Unidos e Reino Unido, foram os cinco primeiros colocados em Inovação, índice que contempla, além de tecnologia, outros aspectos importantes para o desenvolvimento e uso das tecnologias digitais. O Brasil, por exemplo, está em 69a na classificação global de inovação e ocupa a 85a no ranking mundial, no quesito tecnologia (Índice Global de Inovação, 2017, p. 115).

A presença e a influência das tecnologias digitais, contribuem para a variedade cultural de um país. Hall (2006, p. 68), afirma: "Essas novas características temporais e espaciais, que resultam na compressão das distâncias e de escalas temporais, estão entre os aspectos mais importantes da globalização a ter efeitos sobre as identidades nacionais." Esse encurtamento de tempo e espaço acelera o processo de transferência de tecnologias, de comportamentos, de modelos de vida, uma vez que, por meio de smartphones, ocorre o intercâmbio entre pessoas de diferentes culturas. Esse contato possibilita que os indivíduos se relacionem, conversem, negociem, troquem experiências e serviços. Esta interação mediada pela tecnologia de forma a não respeitar o espaço e tempo como nas culturas anteriores, faz com que haja mudanças no comportamento dos indivíduos, o que contribui para a variedade cultural de uma sociedade.

Ainda segundo Hall (2006, p. 47), quando diz “...cultura nacional como comunidades imaginadas...", aponta que "constrói identidades que são colocadas do modo ambíguo entre o passado e o futuro". Alguns aspectos dessa comunidade imaginada são desmistificados pela geração digital. Um exemplo muito simples é quando uma criança (hoje em idade adulta) iniciou seus estudos de história e aprendeu que o Brasil foi descoberto por alguém no ano 1500 e esse aprendizado foi por meio de um livro, um ensinamento unidirecional. Atualmente com o acesso a internet, o campo de pesquisa aumenta, pois não se trata mais apenas de um único livro, e sim de diversos artigos científicos que trazem uma visão crítica; e então, aquela criança percebe que não foi uma "descoberta", já havia moradores, o país já era habitado. Acesso a informações como essas tem impacto direto na formação e na identidade, por referenciar uma história diferente às pessoas que viviam anteriormente, apenas, como receptoras passivas da história de seu país. Além de proporcionar um canal de conhecimento local, com maior embasamento às pessoas, as tecnologias digitais também passam a permitir o acesso a histórias de outros países.

A interação entre pessoas de diferentes países está cada vez mais comum por meio da tecnologia digital. Representações de diversas culturas são difundidas; ambas as partes recebem e emitem novos conceitos de vida e de novas maneiras de resolver um problema ou simplesmente cooperam entre si. Além disso, por intermédio das tecnologias digitais, pessoas deixaram de ser

\footnotetext{
${ }^{4}$ Empresas de tecnologias que iniciam com time, normalmente, pequeno e trabalho com baixos custos, buscam a inovação e tornarem-se exponenciais.
} 
expectadores para também serem protagonistas na cultura de um país: transformaram-se em produtores de conteúdo. Se compararmos à televisão, na qual apenas se via produções culturais e tipos de representação da cultura de um lugar, as aplicações digitais possibilitaram a interação, a resposta, e a representação por diversos atores na sociedade. As produções de vídeos como no Youtube ou Vimeo, ou produções de artigos em plataformas como Linkedln ou blogs influenciaram o comportamento das pessoas. De acordo com Prensky (2001), no artigo sobre os alunos de ensino superior, o modelo mental das pessoas mudou:

\begin{abstract}
Agora fica claro que como resultado deste ambiente onipresente e o grande volume de interação com a tecnologia, os alunos de hoje pensam e processam as informações bem diferentes das gerações anteriores. Estas diferenças vão mais longe e mais intensamente do que muitos educadores suspeitam ou percebem. "Tipos distintos de experiências levam a distintas estruturas de pensamento," diz Dr. Bruce D. Barry da Faculdade de Medicina Baylor. [...] nós podemos afirmar apenas com certeza que os modelos de pensamento mudaram. (PRENSKY, 2001, p. 1 tradução nossa).
\end{abstract}

As terminologias utilizadas por Prensky (2001) ajudam a compreender as diferenças culturais existentes entre as pessoas que nasceram e cresceram com o uso das tecnologias e as que não. Há de se ressaltar, no entanto, que a discussão em torno de Nativos Digitais e Imigrantes Digitais está fora do foco deste artigo. Não se busca aqui defender esses termos, a Geração Digital é compreendida por pessoas que acessam as tecnologias digitais, independente de geração, idade ou qualquer outra característica que venha a classificar as pessoas. A situação social do indivíduo tem muito impacto, no que diz respeito ao acesso as tecnologias digitais.

Não se trata dos artefatos digitais em si, e sim, da maneira como as pessoas passam a interagir com essas tecnologias. Consequentemente, para o bem ou para o mal, passam a mudar sua maneira de viver e constroem novas maneiras de se relacionar com os outros e a adquirir novas referências que representem e construam os símbolos, significados e significantes de uma variedade cultural, e desta forma o surgimento de uma Cultura Digital.

\title{
3 Cultura Digital
}

A geração digital, por meio do smartphone, conecta-se a diversos aplicativos, anteriormente utilizados isoladamente. Os artefatos: agenda em papel, relógio de pulso, aparelho MP3, câmera fotográfica, aparelho de calculadora, calendário em papel, bloco de anotações, filmadora, computador e tantos outros, foram substituídos por aplicativos digitais (Figura 2). A partir dessas mudanças, outras funcionalidades passaram a existir e a atender as necessidades das pessoas. Não há consenso na definição da terminologia para o período da história em que vivemos, há autores que definem como Era da Informação (CASTELLS, 1999), Cibercultura (LEVY, 1999), Era Digital (PALFREY e GASSER, 2017), todavia, todos apontam a forte presença das tecnologias digitais na vida humana. 
Figura 2: Os artefatos foram substituídos pelos aplicativos e transformou a experiência de uso das pessoas.

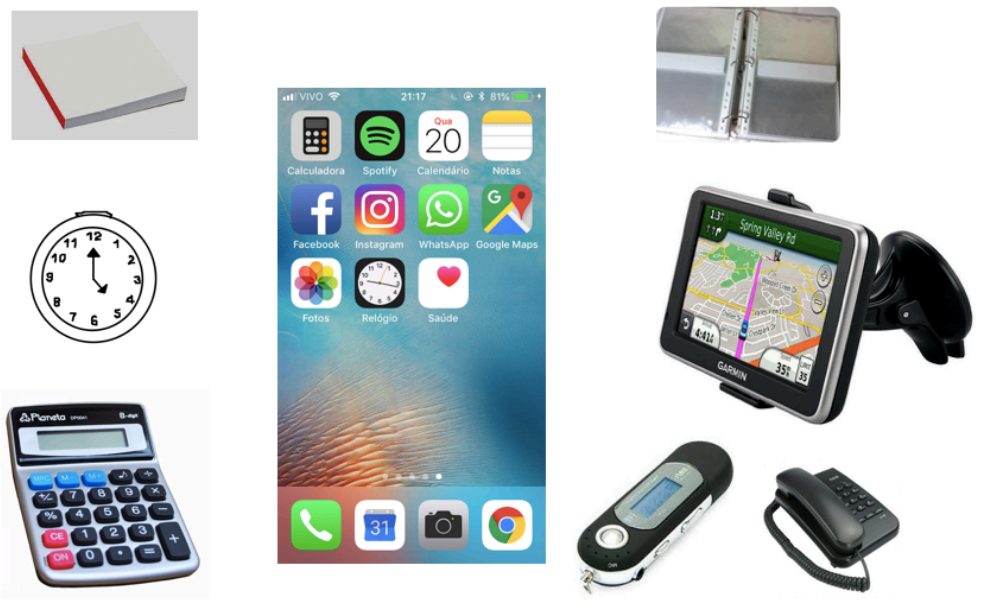

Fonte: Arquivo próprio dos autores e internet.

Adicionalmente à era em que estamos, a forte presença da tecnologia digital, que leva diversos autores a definirem esse período da história, com base nestes artefatos, temos uma definição para Cultura, abordada por Gere (2008):

[...] é possível propor a existência de uma cultura digital distinta, na medida em que o termo digital pode representar um modo particular de vida ou um grupo ou grupos de pessoas em um determinado período da história [...]. A digitalidade pode ser pensada como um marcador de cultura porque engloba os artefatos e os sistemas de significação e comunicação que demarcam mais claramente nosso estilo de vida contemporâneo dos outros. (GERE, 2008, p. 16, tradução nossa).

Um exemplo muito claro de como as pessoas se relacionam, comunicam e até mesmo prestam serviços para diferentes pessoas em diferentes lugares, apenas para citar, é a rede social de negócios Linkedin Corporation em que seus usuários podem se conectar à pessoas de outros países, conhecer profissionais de diversas áreas e estabelecer relações comerciais a partir das funcionalidades que a plataforma ou o aplicativo para smartphones disponibilizam. Existe, além do aplicativo da rede social, um segundo aplicativo interligado e responsivo ao LinkedIn chamado de Linkedln Jobs que disponibiliza às pessoas oportunidades de emprego. Esse aplicativo demonstra como mudou, em alguns países, a forma das pessoas realizarem contatos profissionais. Em vez de um currículo ou de uma eventual apresentação a outro profissional em um evento, o aplicativo possibilita que as pessoas avaliem umas às outras e classifiquem as suas competências. Em apenas esse exemplo, podemos perceber a mudança comportamental delas. A necessidade de se qualificar e obter habilidades vai além dos títulos, pois as indicadas pelas pessoas, no LinkedIn, são normalmente precedidas de uma se relacionar com a outra e de terem conhecido pessoalmente os conhecimentos que cada uma possui. Com isso, os usuários deste serviço validam a expertise do outro, por meio do aplicativo Linkedln, ou seja, o outro usuário confirma os títulos daquela pessoa (Figura 3). Essas informações são utilizadas por recrutadores ou por qualquer pessoa da rede interessada num perfil profissional tanto para uma parceria ou para alguma troca de 
experiência.

Figura 3: Indicações de competências da rede social de negócios LinkedIn.

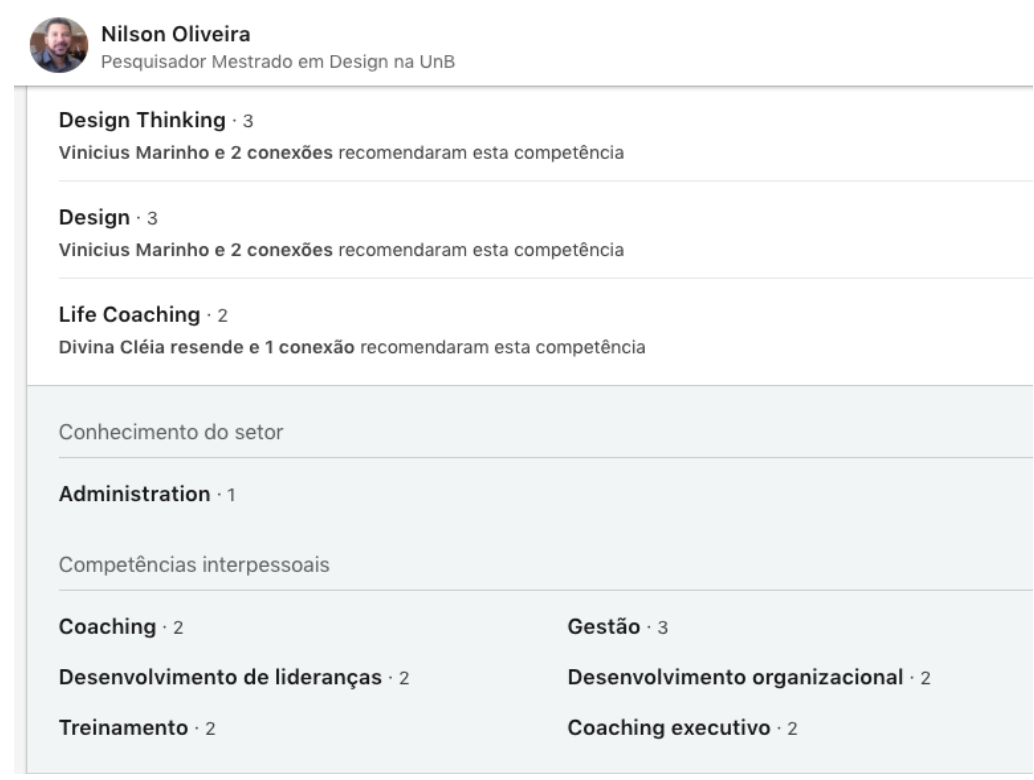

Fonte: Linkedln, arquivo próprio dos autores.

Funcionalidades como essa se repetem em diversos outros aplicativos, o que demonstra tendência de uma característica comportamental das pessoas em não buscarem mais mediadores institucionais ou "formais" para terem acessos a serviços ou pessoas. Está na rede; é acesso público; basta interagir e existir congruência entre as partes para acontecer a transferência de conhecimento, a prestação de serviços ou a conexão entre pessoas, inclusive, de diferentes países:

A característica mais preeminente do atual estágio cultural é que a produção e distribuição dos produtos culturais agora adquiriram, ou estão em vias de adquirir, grande dose de independência em relação às comunidades institucionalizadas, em particular às comunidades territoriais politicamente institucionalizadas. (BAUMAN, 2012, p. 47).

As tecnologias digitais mudaram a forma como as pessoas interagem entre si, muito em função da influência que as aplicações para smartphones proporcionam. Exemplos de diferentes serviços, como Uber, Airbnb e Netflix proporcionam experiências de transporte individual ou coletivo, hospedagem em um quarto residencial a um palácio e acesso a diversos seriados e filmes respectivamente por meio de seus aplicativos para smartphones. A redução do custo de banda larga, dados $3 G$ ou $4 G$ e mais recentemente, no Brasil o $4,5 G^{5}$, contribuíram para o fortalecimento da cultura digital à medida que mais pessoas passam a ter acessos e a usarem os serviços disponíveis.

Cultura Digital é compreendida pelo comportamento observado a partir da interação das pessoas com acesso e uso de tecnologias digitais, desde aquelas objeto deste artigo (aplicativos para smartphones) até aquelas disponíveis em outros meios de interação. As pessoas passam a interagir com as outras por meio destas tecnologias, usam-nas para seu trabalho diário e para seu lazer e ao sair de casa, em muitos casos, retornam para buscar seu smartphone, pois sentem-se

\footnotetext{
${ }^{5} \mathrm{O}$ "G" refere-se à geração de tecnologia que tem como base a transmissão de dados de internet.
} 
sem uma "parte de seu corpo", ou seja, é parte de seu cotidiano o acesso e o uso das aplicações digitais.

Quando Prensky (2001, p.1) cita “... passaram a vida inteira cercados e usando computadores, vídeo games, tocadores de música digitais, câmeras de vídeo, telefones celulares, e todos os outros brinquedos e ferramentas da era digital", e que os imigrantes digitais, adaptaram-se ou aprenderam com os mais novos a usarem essas tecnologias, entendemos que o autor, à época, buscava esclarecer as diferenças culturais entre aqueles que nasceram no período digital e os que não. Todavia, conforme mencionado anteriormente, para efeitos deste artigo, o fato das pessoas usarem, sistematicamente, as tecnologias digitais, já as inserem na cultura digital definida por Gere (2008). O que muda são os níveis de acesso e de uso das tecnologias. Não se pode aqui, excluir alguma pessoa, apenas por razão dela não ter ainda "migrado" completamente para o digital. $\mathrm{O}$ uso, unicamente, por exemplo, de aplicativo de mensagens instantâneas por parte de uma pessoa idosa, já demonstra mudança de atitudes encontradas na cultura digital. Assim, grosso modo, poderíamos considerar que ela, na linha do tempo, deslocava-se a pé ou por algum meio de locomoção à época, para conversar com outra pessoa, em seguida, com o advento da telefonia, realizava ligações de sua residência, depois por meio de celulares, em qualquer lugar, e hoje, por intermédio de smartphones, em vez de ligar, usa um aplicativo de mensagens instantâneas para conversar por meio de mensagens de áudio ou por videoconferência.

Essa situação apresentada demonstra as mudanças causadas ao longo do tempo, devido as tecnologias, e a última citada de enviar mensagens de áudio, demonstra que um único acesso ao aplicativo de mensagens instantâneas, altera, em alguns momentos, o ato de ligar ou de deslocamento e acrescenta novas maneiras de interagir: conversar por meio de videoconferência, em vez de apenas por áudio. A cultura digital está representada pela presença das aplicações digitais na vida das pessoas, seja por meio de smartphones, ou por outros canais. Independentemente do nível de acesso ou uso, consideramos a pertença delas a essa cultura, à medida que tem algum tipo de influência por estes artefatos. Dentro desse universo, o que se pode analisar, em pesquisas, são os níveis de acesso e entender quais são os tipos de influências existentes na vida das pessoas ou ainda, de dependências existentes:

São tantos os benefícios e potencialidades de uso que muitos jovens e adultos de hoje não podem imaginar uma existência sem smartphones. Eles são vistos como fundamentais para manter relações sociais e na condução das exigências da vida cotidiana. É muito comum que as pessoas vejam seus smartphones como parte integrante de quem eles são, ou como uma importante extensão de si mesmos. A possibilidade de se comunicar de diferentes formas em qualquer lugar e a qualquer momento também abre espaço para que $o$ uso do smartphone interfira negativamente em nosso cotidiano. Estudos demonstram que indivíduos que fazem uso excessivo de smartphones apresentam sintomas e prejuízos semelhantes aos encontrados em sujeitos com outros tipos de dependências, tanto químicas quanto comportamentais [...]. (PICON et al, 2015, p. 10).

Assim, existe o pertencimento a esta cultura, o que se há de observar além dos níveis de acesso são as aplicações que usam. Essa definição de aplicações ajuda a entender as expectativas de uso, como por exemplo para aquelas, talvez, menos comuns para o cotidiano, com natureza diferente de redes sociais: as bancárias. Esse acesso e uso se diferencia das demais, todavia os níveis de exigências dos usuários de serviços financeiros não são diferentes.

Está cada vez mais comum, por meio de um smartphone, efetuarmos uma transferência bancária, por exemplo, durante um café com amigos, e mais comum ainda, simularmos, no 
aplicativo mobile banking, o financiamento de uma casa, ou consórcio de um carro no domingo à tarde ao lado das pessoas que amamos e planejamos o nosso futuro. Situações como essas se repetem em diversos outros serviços, o que demonstra uma mudança na forma como as pessoas ficam sabendo, analisam, simulam e contratam os serviços. Para uma parcela de pessoas que usa os serviços digitais, todo o processo de compra, da escolha à aquisição final, acontece por meio dos aplicativos para smartphone. Para outra parcela, apenas uma parte do processo, como: pesquisar e comparar preços e ler comentários sobre a qualidade do produto são realizadas por meio de um aplicativo, pois o restante, o ato comprar, é feito diretamente em uma loja física.

\section{Evolução da Tecnologia Bancária}

O desafio atual do setor financeiro tem sido usar o design para resolução de problemas e concepção ou melhoria de produtos e serviços. A prioridade central é realizar a transformação digital, pois além de proporcionar melhor experiência aos seus usuários, reduz custos operacionais. Segundo Castro (2015, p. 15) "uma das razões fundamentais para o desenvolvimento dos bancos em relação a tecnologia é referente a economias de custos, oferecendo serviços bancários on-line, a um custo menor em relação ao tradicional sistema bancário." Os aplicativos para smartphones têm se apresentado como a tecnologia escalável no concorrido mercado financeiro, e que também permite ao cliente se "auto" atender sem necessidade de deslocamentos ou enfrentar filas de espera nos ambientes presenciais e em centrais de atendimento.

Para Castro (2015, p. 16) "em alguns setores, como de serviços financeiros, o consumidor tornou-se o próprio produtor, permitindo assim que, por meio da tecnologia, ocorra a padronização nos serviços prestados." A transformação digital vem como uma interface que melhora a experiência das pessoas no uso dos produtos e serviços bancários. No entanto, na maioria das vezes, as mudanças ocorreram nos processos internos dos bancos:

\footnotetext{
Observou-se que no desenvolvimento dos produtos, a fase que exige maior emprego de tempo é o alinhamento do produto à estratégia da organização. Nesse sentido, a definição do conceito do produto é crucial e é essa fase que demanda mais tempo no desenvolvimento da inovação. [...] Outro aspecto importante referente ao CDC tradicional diz respeito à sua evolução ao longo de sua existência. Esse produto pouco se modificou em termos que o cliente pudesse perceber (Front Office), entretanto, grandes e significativas foram as alterações ocorridas em seus processos internos ao Banco A (Back Office). (FACÓ; DINIZ; CSILLAG, 2009, p. 193).
}

Essa maneira de desenvolvimento difere da abordagem que Preece, Rogers e Sharp (2005) afirmam que há a necessidade de se realizar pesquisas etnográficas sob a perspectiva do design para entender como as pessoas vivem, quais são as suas necessidades e para descobrir e interpretar o que realmente os usuários precisam. Nesse processo de etnografia para compreender as emoções, as jornadas de uso, e quais são as necessidades dos usuários dentro de uma perspectiva de uma cultura digital, é necessário, assim, estarmos atentos ao que Bonsiepe (2011) cita sobre a necessidade de alteridade nesse processo de etnografia. $O$ autor menciona sobre a disposição que devemos ter em respeitar as outras culturas projetuais com seus valores inerentes, e não as vê com um olhar explorador em busca da próxima tendência de curta duração no mercado. Alerta também, que é necessário convergir com equilíbrio às metas estabelecidas pelo mercado e o atendimento às necessidades dos usuários. O que demonstra que no design de serviços é razoável termos em mente que uma cultura precisa ser respeitada. Mesmo que se tenha o desejo de transformar digitalmente é preciso ter um olhar para a maneira como as 
pessoas se relacionam com as tecnologias digitais, e então apontar para o setor os caminhos a serem seguidos neste processo de transformação. É certo que, nem sempre, todas as propostas do designer serão aceitas pelo mercado, por isso, o equilíbrio citado por Bonsiepe (2011). Todavia, o importante é envolver esses usuários no processo de criação, torná-los produtores de serviços, como o são em outras tecnologias.

O setor buscou, na tecnologia, uma maneira de oferecer mais canais de atendimento aos seus clientes, incialmente com o objetivo de reduzir as transações realizadas nas agências:

\begin{abstract}
A partir da década de 1980, os bancos começaram a utilizar uma distribuição multicanal dos seus produtos e serviços, não só através da rede de agências físicas como também por caixas eletrônicos e atendimento telefônico, já com os avanços tecnológicos na década de 1990, houve aumento significativo do volume de transações bem como acesso a novos produtos estavam disponíveis fora do ambiente físico da agência, culminando na criação do internet banking (BLACK et al; 2002, apud CASTRO, 2015, p. 22).
\end{abstract}

É nesse cenário que a ida de clientes a uma agência começou a reduzir, pois o ato de realizar depósitos em cheques, transferências, consultas de saldos e extrato, passou a ser realizado por meio de serviços digitais para uma parcela dos usuários do serviço. Conforme apontam Tachizawa, Pozo e Furlaneti (2017), a redução de custos em deslocamentos e a flexibilidade de horários são um dos exemplos que os serviços digitais proporcionam aos seus usuários. Ao mesmo tempo, citam os mesmos autores, que clientes entrevistados que utilizam o serviço digital bancário, têm insatisfação quanto aos demais serviços que ainda necessitam de entrega de documentos, assinaturas de contratos, bem como a ausência de informações claras dos produtos bancários, o que levam os usuários a buscarem o atendimento presencial nas agências bancárias.

Esse fato causa uma descontinuidade no atendimento digital, pois o cliente tem parte do serviço pelos canais disponíveis através da internet e outra somente nas agências de relacionamento, ou seja, presencialmente no espaço escolhido pelo fornecedor do serviço. Em meio às ineficiências existentes, insatisfação de clientes e à concorrência, em especial as fintechs ${ }^{6}$, o setor busca a transformação digital. Ir além da disponibilização de consulta a extratos e de serviços de transferências e pagamentos, isto é, tem o objetivo de popularizar o uso de aplicativos para smartphones para atender as necessidades dos usuários por meio de uma gama maior de serviços financeiros. A lógica aqui muda, de serviços bancários, para serviços financeiros, e resulta, portanto, em atender as pessoas em situações relacionadas a seus eventos de vida e não simplesmente ao cumprimento de metas do funcionário que atende ao cliente.

Está entre os desafios do setor, tanto o acompanhar a evolução do mercado quanto o compreender as mudanças comportamentais de seu público. Os perfis comportamentais das pessoas, como cultura e identidade devem ser compreendidas, avaliados e considerados desde a concepção dos serviços bancários. Para Facó, Diniz e Csillag (2009) existe uma relação entre a oferta e a demanda no processo de desenvolvimento de produtos bancários e o perfil do consumidor é um dos influenciadores nas decisões dos bancos:

O desenvolvimento de novos produtos no setor bancário pode ser visto ainda a partir da influência dos fatores de mercado ligados tanto à oferta quanto à demanda. Pelo lado da oferta, os bancos concorrem para se diferenciar e atender a segmentos específicos de

\footnotetext{
${ }^{6}$ São empresas de tecnologia que oferecem serviços financeiros, exclusivamente por meios digitais, ex. PagSeguro e Nubank.
} 
mercado, que podem ter características bastante diferentes. Pelo lado da demanda, as mudanças no perfil dos clientes dos serviços bancários também pressionam os bancos a buscarem novas alternativas de produtos e serviços que venham a satisfazer seus clientes. (FACÓ; DINIZ; CSILLAG, 2009, p. 183).

Os investimentos do setor financeiro em tecnologia, historicamente, têm se voltado para infraestrutura de produção, armazenamento e manutenção das cópias de segurança de documentos digitais, o que tornou por muito tempo a principal tarefa das tecnologias bancárias. Esse cenário começa a modificar a partir do momento em que os bancos passam a investir em tecnologias digitais para seus clientes:

De uma forma geral, nos seus estágios iniciais elas apontam para um uso de TI ainda restrito a sistemas centrais de processamento e compensação de transações, e, portanto não visível pelos clientes; ao passo que nas fases subsequentes elas descrevem um processo pelo qual a TI se torna cada vez mais próxima do cliente. Em todas as periodizações a fase final ou mais recente é apontada como sendo aquela que envolveu a implantação e difusão de tecnologias relacionadas aos serviços de home banking e de Internet banking. (CERNEV, DINIZ e JAYO, 2009, p. 01).

A normatização do Banco Central do Brasil através da Resolução 4.474/2016, que regulamenta o processo de digitalização de documentos nos bancos, estabelece os procedimentos para a produção e a gestão de documentos digitalizados pelo agente financeiro, o que a torna um marco para o setor, no processo de transformação digital, pois, regulamenta a aceitação de documentação por meio digital. Anteriormente, a exigência era sempre a apresentação de originais ou cópias autenticadas em cartório. Todavia, ao mesmo tempo em que possibilita aos bancos a digitalização dos serviços bancários, as regras estabelecem rigor no controle, cópias de segurança e de rastreabilidade. É complexo realizar a transformação digital, a partir das exigências dessa resolução, em uma interface amigável para o usuário final do serviço. Segundo Facó, Diniz e Csillag (2009) as regulamentações que pesam sobre esse setor influenciam o surgimento de novos serviços, mas servem também para impulsionar ou restringir a difusão no mercado. É nesse ponto que o design de serviços entra como um processo resolução de problemas complexos, conforme aponta CARDOSO (2012):

A "era da informação" chegou para todos - por meio de mudanças essenciais em sistemas de fabricação, distribuição e finanças - e não somente para quem tem computador pessoal em casa. À medida que o mundo virtual aumenta em abrangência, a realidade parece desmanchar-se no ar. Em uma palavra o imaterial passou a ser fator decisivo em quase todos os domínios, mormente numa área como o design. (CARDOSO, 2012, p. 91).

Tem se observado que a estratégia de transformação digital da indústria financeira possui como um de seus objetivos o ganho de eficiência operacional com foco em redução de custos, conforme apontam Cernev; Diniz e Jayo (2009) "uma quinta onda da inovação em tecnologia bancária está relacionada ao interesse estratégico dos bancos em ampliar a sua base tradicional de clientes." Os canais de atendimento por meio de aplicativos, como chat ou videoconferência, por exemplo, viriam a proporcionar uma melhor experiência aos usuários. Abertura de contas e contratações de crédito por meio de aplicativos, ou solicitações de cartões de crédito diretamente pelo smartphone são algumas das funcionalidades que o setor tem investido para manter e ampliar sua base de clientes.

Com o crescimento de acessos à internet por meio de smartphones, existe um fator que chama atenção: o foco da produção tecnológica voltada para esse meio com expectativa de alcance à pessoas de diferentes idades. Conforme mencionamos anteriormente, entendemos 
como parte da Geração Digital, pessoas que acessam ou usam as tecnologias digitais, independente de idade, pois, a idade tem sido a mais comum entre autores para definir as gerações, todavia, com base nas revisões bibliográficas, observa-se que esta é apenas uma das variáveis a serem analisadas quando se pensa em observar os comportamentos de usos tecnológicos de uma sociedade. Desta forma, se há o intuito em alcançar pessoas de diferentes conhecimentos e níveis de acessos a essas tecnologias haveria uma estratégia coerente com o que acontece com o aprendizado das demais tecnologias digitais, por parte daqueles que começam a aprender a usá-las. A ressalva está em respeitar as experiências e desejos dos clientes: há aqueles que não se sentem à vontade em realizar movimentações financeiras por meio de um smartphone; assim, os bancos precisam compreender esse público e criar ou manter atendimento de acordo com as expectativas desses usuários.

A corrida agora é ir além de transações bancárias. É permitir aos usuários adquirirem serviços financeiros por meios digitais, serviços estes, que gerem valor à vida das pessoas e isso requer entender as necessidades dos usuários e daqueles que ainda não tem acesso a estes serviços. É ir além das expectativas do cliente e oferecer-lhe serviços que dêem continuidade na comunicação e contratação em qualquer canal desejado. As tecnologias atuais permitem uma série de inovações para o setor e podem mudar a forma como as pessoas se relacionam com os bancos: o uso de inteligência artificial para chats, a internet das coisas para compras diretas sem intervenção humana e a identificação por meio de biometrias.

\section{Considerações Finais}

A digitalidade das coisas influenciou os meios de comunicação, as interações entre as pessoas e o comportamento humano. Houve um impulso na transferência de tecnologias digitais dos países do Centro para os da Periferia. É, desta forma, relevante para a sociedade, o aprofundamento sobre as interações humanas com as aplicações digitais, por meio do design de serviços, a fim de obter, por intermédio de entrevistas ou observação, elementos que ampliem os conhecimentos sobre a cultura digital.

O comportamento dessa geração é, sobretudo, uma gama enorme de elementos a se buscar investigação para ampliar o conhecimento acerca da Geração Digital, para obtenção de um correto embasamento, em vez de fecharmos conclusões que não retratem o que realmente motiva a geração digital no seu cotidiano. As reflexões do presente artigo nos despertam, à luz do entendimento de alguns aspectos sobre a Geração Digital, que as pesquisas neste campo são riquíssimas para a compreensão dos aspectos chave de uma cultura que passa por mudanças contínuas, uma vez que as tecnologias nascem quase obsoletas, com mudanças e avanços constantes, que alteram a maneira como o ser humano vê e encaminha as relações pessoais e comerciais.

A Geração Digital, aqui definida, como as pessoas que têm acesso e usam de maneira sistemática as tecnologias digitais para smartphones, pois, não se generaliza, ou não se tem pretensão alguma em caracterizar a sociedade em geral, como pertencentes à geração digital. 0 recorte se dá no acesso e uso destes artefatos, uma vez que precisamos considerar aquelas pessoas que não possuem as tecnologias disponíveis em smartphones, pois, conforme as pesquisas supracitadas neste artigo, não há $100 \%$ de pessoas conectadas por meio do equipamento. Há que se considerar, portanto, a delimitação da visão de entendimento de alguns aspectos sobre a geração digital descrita neste artigo. Este tem sido um cuidado constante em não 
generalizar a terminologia Geração Digital a todas as pessoas de uma nação, em sintonia com o que Bauman (2012) cita sobre a inexistência de uma cultura como totalidades distintas.

A perspectiva da continuidade deste estudo é buscar características de pessoas com base no acesso e nos níveis de uso das tecnologias digitais, para, a partir daí, compreender que comportamentos são encontrados de acordo com o uso e não idade ou pertença a uma geração ou outra. Essa perspectiva evita a discussão acerca de estabelecimentos de "gerações", que muitos autores críticos envidam esforços por ela e encontram exatamente o que os autores propõem: a pertença a uma geração não é fator decisivo para definir o quanto uma pessoa conhece e é influenciada pelo digital, e sim os seus níveis de uso e de acesso.

\section{Referências}

AGÊNCIA BRASIL. Celular é principal meio de acesso à internet no Brasil, mostra IBGE. Disponível em <http://agenciabrasil.ebc.com.br/economia/noticia/2016-04/celular-e-principal -meio-deacesso-internet-na-maioria-dos-lares> Acesso em 04/Nov/2011 às 23:14:58.

BAUMAN, Z. Ensaios sobre o conceito de Cultura. Rio de Janeiro: Editora Jorge Zahar, 2012.

BANCO DO BRASIL S.A. Banco do Brasil instala laboratório no Vale do Silício. Disponível em http://www.bb.com.br/pbb/pagina-inicial/imprensa/n/53743/banco-do-brasil-instala-laboratoriono-vale-do-silicio\#/ Acesso em 31/Mar/2018 às 14:43:29.

BONSIEPE, G. Design, cultura e sociedade. São Paulo: Blucher, 2011.

CARDOSO, Rafael. Design para um Mundo Complexo. São Paulo: Cosac \& Naif, 2012.

CASTELLS, M. A era da informação: Economia, Sociedade e Cultura. A sociedade em Rede. São Paulo: Paz e Terra, 1999.

FILHO, J. C. T. Proposta de análise do banco virtual no contexto dos canais bancários e da aceitação do cliente. Biblioteca Digital FGV, 2015. Disponível em < http://hdl.handle.net/10438/15039> Acesso em 04/Out/2017 às 19:27:18.

CERNEV, A.; DINIZ, E.; MARTIN, J. Emergência da quinta onda de inovação bancária. AMCIS 2009 Proceedings. 4. Disponível em <http://aisel.aisnet.org/amcis2009/4> Acesso em 27/Set/2017 às $15: 44: 21$.

CETIC.BR. TIC Domicílios 2016, indivíduos. Disponível em: < http://www.cetic.br/tics/domi cilios/2016/individuos/> Acesso em 02/Nov/2017 às 17:18:32.

CORD, F. H.; BRAIDO, G. M. Fatores que inibem a utilização do mobile banking: um estudo com estudantes de uma instituição de ensino superior do Rio Grande do Sul, 2017. CONTECSI USP. Disponível em: http://www.contecsi.fea.usp.br/envio/index.php/contecsi/14CONTECSI/paper/viewPaper/4441> Acesso em 27/Set/2017 às 14:59:23.

FACÓ, J. F., DINIZ, E. H., e CSILLAG, J. M. (2009). O processo de difusão de inovações em produtos bancários. Revista de Ciências da Administração, 11 . Disponível em < http://www.redalyc.org/html/2735/273520578007/> Acesso em 27/Set/2017 às 18:23:37.

FIEBIG, É. A.; FREITAS, E. C. Canais de atendimento, satisfação e lucratividade de clientes em serviços: um caso bancário. Revista Eletrônica de Administração, v.17, n.3, p.742-775, 2011. Disponível em <http://www.seer.ufrgs.br/read/article/view/38521> Acesso em 04/Out/2017 às 
18:59:02.

GERE, C. Digital culture. London: Reaktion Books, 2008.

HALL, S. A identidade cultural da pós-modernidade. São Paulo: DP\&A editora, 2006.

IANNI, O. Globalização e Transculturação. Revista de ciências humanas, v. 14, n. 20, p. 139-170, 1996. Disponível em < https://periodicos.ufsc.br/index.php/revistacfh/article/ viewFile/23492/21159> Acesso em 05/Nov/2017 às 11:28:02.

LEVY, P. Cibercultura. São Paulo: Ed. 34, 1999.

PALFREY, J.; GASSER, U. Nascidos na Era Digital: Entendendo a Primeira Geração de Nativos Digitais. Ed. Penso, Edição 1, 2017.

PICON F., KARAN R., BREDA V., RESTANO A., SILVEIRA A., SPRITZER D. Precisamos falar sobre tecnologia: caracterizando clinicamente os subtipos de dependência de tecnologia. Rev. bras. psicoter. 2015. Disponível em < http://www.rbp.celg.org.br/detalhe_artigo.asp?id=177> Acesso em 31/Mar/2018 às 19:08:37

PRENSKY, M. Digital Natives, Digital Immigrants Part 1, On the Horizon, Vol. 9 Issue: 5, pp.1-6, 2001. Disponível em <https://doi.org/10.1108/10748120110424816> Acesso em 02/Nov/2017 às 14:57:30.

SIMÕES, L.; GOUVEIA, L. (2008). Geração Net, Web 2.0 e ensino superior. Cadernos de Estudos Mediáticos, 6, 21-32. Disponível em >https://pdfs.semanticscholar.org/b59d/fd265ad7bdbad0388d4e4eaa6cae2b31c454.pdf< Acesso em 23/Jun/2017 às 20:12:22.

TACHIZAWA, T.; POZO, H.; FURLANETI, E. W. Atendimento bancário digital: Estudo de caso em microempresas. Revista Ciências Sociais em Perspectiva, v. 16, n. 30, p. 1-21. Disponível em: <http://e-revista.unioeste.br/index.php/ccsaemperspectiva/article/view/16490> Acesso em: 25/Jun/2017 às 22:07:17.

TIC DOMICÍLIOS - 2016. Centro Regional de Estudos para o Desenvolvimento da Sociedade da Informação. Cetic.br. Disponível em: <http://www.cetic.br/tics/domicilios/2016/individuos/J7/> Acesso em 10/Out/2017 às 09:29:33.

UNIVERSIDADE CORNELL, INSEAD e WIPO (2017): Índice Global de Inovação de 2017: A Inovação Nutrindo o Mundo, Ithaca, Fontainebleau e Genebra. Disponível em <http://www.portaldaindustria.com.br/publicacoes/2017/11/indice-global-de-inovacao-de-2017inovacao-nutrindo-o-mundo/> Acesso em 30/Mar/2018 às 07:18:09. 